Article

\title{
The Role of Managerial Commitment and TPM Implementation Strategies in Productivity Benefits
}

\author{
José Roberto Díaz-Reza ${ }^{1}$ (D), Jorge Luis García-Alcaraz ${ }^{2, *}$ (D), Liliana Avelar-Sosa 2 (D), \\ José Roberto Mendoza-Fong ${ }^{1}$ (D), Juan Carlos Sáenz Diez-Muro ${ }^{3}$ and Julio Blanco-Fernández ${ }^{4}$ (iD \\ 1 Department of Electrical and Computer Engineering, Universidad Autónoma de Ciudad Juárez, \\ Ciudad Juarez 32310, Mexico; al164440@alumnos.uacj.mx (J.R.D.-R.); al164438@alumnos.uacj.mx (J.R.M.-F.) \\ 2 Department of Industrial Engineering and Manufacturing, Universidad Autónoma de Ciudad Juárez, \\ Juarez 32310, Mexico; liliana.avelar@uacj.mx \\ 3 Department of Electrical Engineering, Universidad de La Rioja, 26006 Logroño, Spain; \\ juan-carlos.saenz-diez@unirioja.es \\ 4 Department of Mechanical Engineering, Universidad de La Rioja, 26006 Logroño, Spain; \\ julio.blanco@unirioja.es \\ * Correspondence: jorge.garcia@uacj.mx; Tel.: +52-656-688-4843 (ext. 5433)
}

Received: 28 June 2018; Accepted: 10 July 2018; Published: 16 July 2018

Featured Application: The findings in this research allow managers to know quantitatively the importance of preventive maintenance in an adequate performance of total productive maintenance and productivity benefits in a production system, allowing them pay attention on those activities that are more important.

\begin{abstract}
The present research proposes a structural equation model to integrate four latent variables: managerial commitment, preventive maintenance, total productive maintenance, and productivity benefits. In addition, these variables are related through six research hypotheses that are validated using collected data from 368 surveys administered in the Mexican manufacturing industry. Consequently, the model is evaluated using partial least squares. The results show that managerial commitment is critical to achieve productivity benefits, while preventive maintenance is indispensable to total preventive maintenance. These results may encourage company managers to focus on managerial commitment and implement preventive maintenance programs to guarantee the success of total productive maintenance.
\end{abstract}

Keywords: TPM; implementation; managerial commitment; productivity benefits

\section{Introduction}

In current industrial scenarios, waste in production processes is frequent, usually the result of the lack of skills of both operators and maintenance staff, not enough machinery available, and issues with work tools [1]. Other types of waste include machinery downtime, not utilizing talents, damaged machinery, and rejected parts, among others [2].

To increase competitiveness, manufacturing companies seek to reduce the activities that add no value to a product but generate cost, and in this sense, one way of reducing waste is to adopt a lean approach. The lean manufacturing (LM) approach aims to reduce the amount of non-value-added activities in the production process, although it also has reported benefits at the administrative level [3]. LM relies on several tools to achieve its goal, and total productive maintenance (TPM) is one of the most important, because it helps companies to minimize waste, such as damaged machinery and unplanned work, and it encourages the development of production plans that prevent machine overload [4]. 
Furthermore, TPM can be defined as an approach that rapidly improves production processes through employee involvement and empowerment [5]. Nowadays, in the restless and uncertain global business environment, well-managed organizations strive to improve their capabilities by operating profitably; in other words, TPM is a tool that, if correctly implemented, can help businesses reach this goal [6].

Currently, TPM is a successful tested LM tool for planning the maintenance of organizational activities, which involve operators and maintenance staff working together as a team [7]. In this sense, TPM is associated with human resources, and it integrates equipment maintenance in the production process to increase machine availability, as well as adding commercial value to the organization [8].

Also, TPM aims to keep production equipment in proper working condition to prevent breakdowns that eventually delay the production process or make unsafe workplaces, thus TPM is one of the main operational activities in quality management systems [8]. Additionally, TPM emphasizes proactive and preventive maintenance to maximize operational production machinery efficiency and decrease the roles of the production and maintenance departments by empowering operators [8]; it improves organizational competitiveness and comprises a powerful and structured approach to changing employee mentality and, consequently, the organizational culture. This also includes employee involvement at all hierarchical levels in all company departments [9]. In addition, it involves member alignment to improve corrective actions associated with safety [7].

Similarly, TPM not only focuses on machine efficiency, but also is an opportune area for continuous improvement, looking for an ideal relationship between people and machines. In other words, successful organizations must be supported by effective and efficient maintenance plans as a competitive strategy [10]. However, production systems are not the only places where TPM can be applied, because other service-based systems need to be in optimal operating condition as well, such as medical equipment and instruments [11].

Because of the benefits that TPM brings to the industrial environment, one of the main academic and industrial concerns is to find its critical success factors (CSFs). Identifying CSFs allows company managers and administrators to prioritize the activities that ensure TPM success. Also, many studies have reported the key activities involved in these TPM factors [12-15] as well as the obtained benefits [16,17]. However, the relationship between these success factors and company benefits have not been clearly defined.

In addition, it is observed that there is an academic and industrial interest to identify the CSFs of TPM, as well as the activities that integrate them $[12-15,18,19]$. Similarly, there are several reports associated with the obtained benefits from proper TPM implementation in production systems $[16,17,20]$; however, the problem is that there are not enough studies that link CSF with obtained benefits, and as a result, it has not been determined which CSFs are crucial for obtaining specific desired benefits.

Kamath and Rodrigues [21] state that the CSFs may be different from one industrial sector to another and that findings cannot be generalized. For example, Chlebus, et al. [22] report on activities associated with TPM in a mine, and Ahuja and Khamba [23] report on manufacturing industries in India. In Mexico there are currently 5518 maquiladora industries with manufacturing and export services, and in Chihuahua state there are 510, and these amount to $9.25 \%$ of the national total. Of those 510 in Chihuahua state, Ciudad Juárez has 332, which is $65.10 \%$ of the state, directly employing 268,761 workers [24]. Those maquiladora companies are characterized by a high technological level that requires a lot of maintenance services, and there are not enough studies indicating which are the CSFs of TPM and the benefits gained in that industrial sector.

Because the relationship between CSFs for TPM and gained benefits is currently an interesting research area, this paper presents a structural equation model that associates three CSFs: managerial commitment, TPM implementation, and PM implementation, which are related to productivity benefits. In addition, findings in this paper will help managers identify the most significant activities to have a successful TPM implementation and guarantee its benefits. 
The purpose of this research is to quantify, through a structural equation model, the impact of managerial commitment, the implementation process, and the plans and programs executed as CSFs for TPM on productivity benefits gained, and it is validated using information from the maquiladora industry in Mexico.

The rest of this paper is organized as follows: Section 2 provides a brief introduction to concepts related to managerial importance in TPM implementation and its benefits, Section 3 presents the research hypotheses that link the studied variables, Section 4 describes the research methodology, Section 5 reports the research findings, and, finally, Section 6 shows the research conclusions and industrial implications.

\section{Maintenance and Concepts}

\subsection{Critical Success Factors of TPM}

CSFs are relevant performance areas that help companies reach desired goals (e.g., TPM goals) [25]. The literature on TPM addresses a large number of CSFs for TPM implementation. For instance, Park and Han [17] consider that a key factor is employee involvement, since the true power of TPM is using employee knowledge and experience to generate ideas to achieve the desired goals and objectives. On the other hand, Ng, Goh and Eze [12] found that human resources elements along with managerial commitment, employee involvement, education, and training are fundamental in TPM.

In their research, Piechnicki, et al. [26] identified a set of critical TPM success factors and grouped them into eight categories: education and training, teamwork, planning and preparation, senior managerial commitment, resistance to change, change of culture, employee involvement, monitoring results, and effective communication; as can be seen, there are a lot of CSF human resources for TPM. However, Hernández Gómez et al. [27] classified three categories for CSF: strategic planning, technical aspects, and human resources development. That list supports the importance of human resources in TPM success.

In a recent study, Gómez, Toledo, Prado, and Morales [14] performed a factor analysis to evaluate 31 key activities in the TPM implementation process, and the results revealed nine critical success factors: strategic alignment, continuous improvement practices, plant distribution, autonomous maintenance, equipment alignment, employee and supplier involvement, cutting-edge technology, technology development, and communication regarding the TPM development process. This research reveals that top managers must be highly committed to TPM, since they provide the necessary implementation resources. Similarly, operators are equally necessary to detect and prevent errors before failures occur; this approach to equipment maintenance is called preventive maintenance, which is another critical success factor of TPM.

\subsection{Preventive Maintenance}

Preventive maintenance (PM) is defined as a set of activities performed at certain times in a planning horizon to extend the equipment life cycle and keep it in satisfactory working condition, and to increase overall system reliability and availability [28]. Such activities are a part of maintenance programs and attempt to minimize the risk of unplanned equipment downtime. According to its nature, PM includes inspection, cleaning, lubrication, adjustment, alignment, and component replacement for machinery and tools in a production process [28].

Those tasks play a vital role in any production process, as they preserve equipment operating under desired long-term specifications [29]. Also, PM has a positive impact on cost, quality, and delivery performance [30], because it minimizes quality costs by keeping the equipment in the best working condition through proper maintenance programs that guarantee a high rate of compliant products [31].

Currently there are studies that reveal the importance of PM in production systems. For example, Eti et al. [32] make an association between the cost of PM and increased reliability of machinery and 
equipment; Anis et al. [33] propose a plan to relate PM program activities with batch size for production lines to minimize the time lost due to stoppages associated with maintenance. Shrivastava et al. [34] state that product quality is not the responsibility of one department, but preventive maintenance and calibration and adjustments in machinery and equipment are essential to guarantee products with specifications required for clients. Finally, given that PM requires stopping machines and equipment continuously, Fumagalli et al. [35] recommend adequate orchestration of maintenance plans with product delivery commitments in the production system.

All of the above show the importance of PM as a work culture focus for conservation of machinery, and this has industrial and academic interest.

\subsection{TPM Benefits}

TPM critical success factors guarantee important benefits. According to Willmott and McCarthy [16], they provide opportunities to develop suitable strategic plans for the company's capabilities, infrastructure, and human resources to support integration between the operation and maintenance departments, and improve business relationships with customers and suppliers. Similarly, Ma et al. [36] reported that TPM increases production system efficiency, brings social benefits, and promotes management systems in production departments. On the other hand, Gupta, Vardhan, and Haque [13] mention that TPM increases employee morale and skills, improves the use of technology, and enhances equipment working conditions and customer satisfaction. Additionally, successful industries that implement TPM increase their overall equipment efficiency (OEE) by $30 \%$, and some have increased OEE by $95 \%$.

In addition, $\mathrm{Ng}$ et al. [37] found that TPM minimizes machine downtime, increases employee motivation, and minimizes accidents. Likewise, Rodrigues and Hatakeyama [38] argue that companies can increase daily production rates with their current productive capacity and workforce if they implement TPM strategies; however, the researchers also claim that many companies tend to spend little time on equipment maintenance and struggle to empower operators to help maintain their equipment.

\section{Hypotheses and Literature Review}

The goal of TPM is to maximize equipment effectiveness by continuously improving availability and preventing failures, but this cannot be achieved without managerial support [39] and employee involvement. Therefore, participation by all employees promotes a preventive maintenance approach based on motivation management and voluntary small group participation [40]. Also, TPM concepts entail a long-term commitment to planning, especially from senior managers, and usually initiates as a top-down exercise, but it can only be successfully implemented as "bottom-up" participation [7]. From this perspective, the operator commitment, performance, and morale reflect the managerial commitment to TPM [41]. In conclusion, managerial commitment is the most essential factor in TPM implementation [39], which is why the first hypothesis in this research can be proposed as follows:

Hypothesis 1. Managerial commitment has a positive and direct effect on TPM implementation.

TPM initiates with senior managers, since they have the power to implement the necessary organizational changes and formulate the required plans, strategies, and policies, which must be aligned with corporate objectives. Also, the maintenance manager is responsible for the effective performance of TPM activities and setting the basic policies and objectives to be reached through a carefully designed plan [39]. Similarly, senior managers should remove the obstacles that interfere with TPM plans and implementation, and they must make sure that such plans are aligned with the company's short- and long-term goals [42]. In other words, because TPM is based on error prevention, it is important to rely on effective preventive maintenance techniques. PM must be aligned with managerial preferences and priorities in a production system, since that guarantees 
workers' acceptance, and it always must be focused on preventing accidents or failures [43]. Therefore, the second hypothesis in this research can be presented as follows:

Hypothesis 2. Managerial commitment has a positive and direct effect on PM implementation.

The main TPM characteristics are economic efficiency, preventive maintenance, improved maintenance capacity, and employee involvement [44]. As Nakajima [45] argues, the main goal in the TPM implementation stage is to increase equipment efficiency through specific techniques, including autonomous maintenance, where employees improve their skills and help to maintain their equipment. From this perspective, it is claimed that PM is part of the organizational culture and an essential component of TPM; that is, there must be an error and failure prevention program to ensure TPM. Therefore, the third hypothesis in this research can be proposed as follows:

Hypothesis 3. PM implementation has a positive and direct impact on TPM implementation.

As Nakajima [46] points out, the main TPM objectives are to improve productivity, increase management efficiency, and eliminate the six types of production waste. In addition, managerial commitment, along with clear and common goals and visible results, creates a responsibility shared by a team and leads to fewer interruptions and higher reliability levels [47]. Therefore, TPM relies on long-term managerial commitment to increase equipment efficiency and efficacy in order to offer the expected benefits [9]. As a result, the fourth hypothesis in this research can be presented as follows:

Hypothesis 4. Managerial commitment has a positive direct effect on productivity benefits.

TPM implementation can minimize waste and redundant work, and increase company profitability and image, which guarantee competitiveness for a company [39]. Likewise, TPM improves OEE, productivity, safety, and quality, and minimizes equipment life cycle costs [48]. In addition, implementing a TPM approach leads to increased efficiency and work quality; minimizes customer complaints, accidents, and internal waste [49]; and improves delivery performance, stock turnover and employee morale, productivity, and performance [50]. Therefore, the fifth hypothesis in this research is proposed as follows:

Hypothesis 5. TPM implementation has a positive direct effect on productivity benefits.

PM is a scheduled activity usually initiated under certain statistical parameters (e.g., average time, usage) that determine when maintenance actions are necessary before entering the risk zone (where the probability of random equipment component failure increases) [51]. In addition, PM must help prevent unplanned equipment downtime and maximize system availability by keeping equipment in proper working condition and improving its availability. PM includes scheduled tasks, such as supervision of hardware replacement and control before the equipment ends its life cycle. Due to these PM activities, there is a direct impact on the production system [52]; the sixth hypothesis in this research can be presented as follows:

Hypothesis 6. PM implementation has a positive direct effect on productivity benefits.

Figure 1 illustrates the established relationships between the studied variables relating CSFs for TPM and gained benefits. 


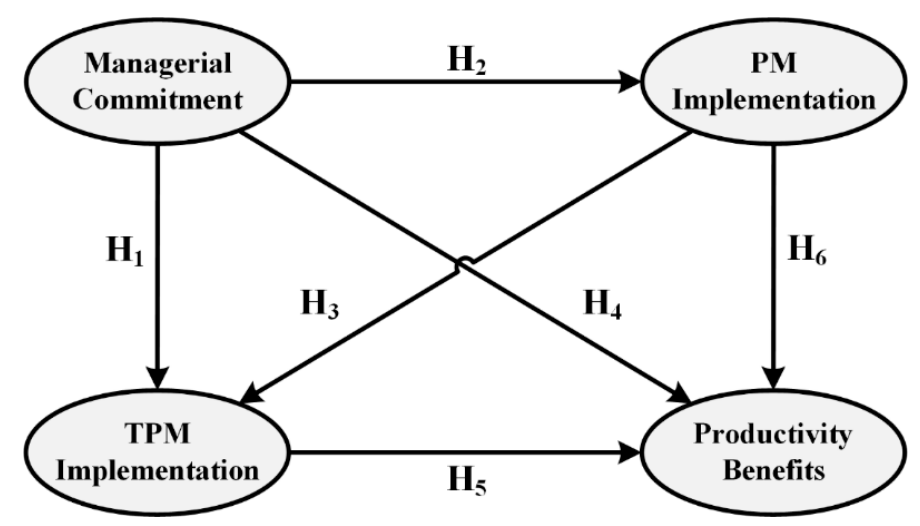

Figure 1. Initial model. TPM, total productive maintenance; PM, preventive maintenance.

\section{Materials and Methods}

\subsection{Stage 1: Survey Design}

In order to validate the model in Figure 1, a survey instrument to gather data was designed. As a matter of fact, designing the survey included reviewing works similar to this research to identify which activities (items) integrate each latent variable (e.g., CSF for TPM and productivity benefits). The previous studies were collected from multiple databases, including ScienceDirect, Springer, and IEEE, among others. This literature review represented validation of the survey's rationale [53] and Table 1 illustrates the CSF for TPM (activities) and productivity benefits gained that were identified.

Table 1. Total productive maintenance (TPM) critical success factors and productivity benefits.

\begin{tabular}{|c|c|}
\hline Latent Variable & Items \\
\hline $\begin{array}{c}\text { TPM implementation } \\
{[4,26,27]}\end{array}$ & $\begin{array}{l}\text { proper education and training of maintenance staff. } \\
\text { follow-up and control of the maintenance program. } \\
\text { commitment from managers and maintenance staff. } \\
\text { managerial leadership in TPM execution. } \\
\text { leadership from production and engineering departments in TPM execution. } \\
\text { maintenance staff leadership in TPM execution. } \\
\text { communication between production and maintenance departments. } \\
\text { knowledge of critical machine systems. } \\
\text { TPM focused on the life cycle of machine systems, parts, and components. } \\
\text { purchase of machines and equipment based on TPM. }\end{array}$ \\
\hline $\begin{array}{c}\text { managerial commitment } \\
{[26,27,39]}\end{array}$ & $\begin{array}{l}\text { department leaders embrace their TPM responsibilities. } \\
\text { top managers lead TPM execution. } \\
\text { meetings are held between production and maintenance departments. } \\
\text { top managers promote employee participation and encourage preservation } \\
\text { of the work team. } \\
\text { top managers develop and communicate a quality- and maintenance-centered vision. } \\
\text { top managers are directly involved in maintenance projects. }\end{array}$ \\
\hline $\begin{array}{l}\text { productivity benefits } \\
{[15,37]}\end{array}$ & $\begin{array}{l}\text { elimination of productivity losses. } \\
\text { increased equipment reliability and availability. } \\
\text { reduction of maintenance costs. } \\
\text { improved final product quality. } \\
\text { decreased spare parts inventory costs. } \\
\text { improved corporate technology. } \\
\text { improved response to market changes. } \\
\text { development of corporate competitive skills }\end{array}$ \\
\hline
\end{tabular}


Next, the identified activities were used to develop a preliminary survey integrated by three sections: sociodemographic information, activities of critical success factors for TPM and PM, and productivity benefits.

\subsection{Stage 2: Survey Administration}

The final questionnaire was given to TPM practitioners in the Mexican manufacturing industry: senior managers, engineers, technicians, supervisors, and operators. In order to select the sample, first a stratified sampling technique was followed; that is, companies with fully consolidated maintenance programs (10 years of implementation or more) that could corroborate such information through equipment maintenance records were identified and considered.

The survey was answered with a five-point Likert scale, as seen in Table 2, through face-to-face interviews. The lowest value on the scale (1) indicated that an activity was never performed or a productivity benefit was never obtained, whereas the highest value (5) indicated that an activity was always performed or a productivity benefit was always obtained. Also, experienced personnel who were interviewed recommended other possible responders, then the snowball sampling technique was implemented.

Table 2. Survey scale.

\begin{tabular}{cccccc}
\hline Value & $\mathbf{1}$ & $\mathbf{2}$ & $\mathbf{3}$ & $\mathbf{4}$ & $\mathbf{5}$ \\
\hline interpretation & never & rarely & regularly & frequently & always \\
\hline
\end{tabular}

\subsection{Stage 3: Data Capture and Screening}

The collected data were registered in a database using SPSS $24^{\circledR}$; the columns represented the survey items and the rows cases or questionnaires. Then, the database was screened by performing the following operations:

- The standard deviation was calculated; if the value was lower than 0.5 , that case was removed, since all the items had a similar value [55].

- The missing values were identified; if a questionnaire had $10 \%$ or more missing values, it was discarded [56]. On the other hand, for questionnaires that had less than $10 \%$ of missing values, such values were replaced with the median in the item [57].

- Outliers were identified by standardizing each item; extreme or atypical observations with an absolute standardized value greater than $4[58,59]$ were replaced by a median value in the item.

\subsection{Stage 4: Survey Validation}

Once the data were evaluated, the 4 latent variables were tested by estimating the following indices proposed by Kock [60]:

- $\quad$ R-squared and adjusted R-squared for the predictive validity of the survey from a parametric perspective; only values over 0.2 were acceptable.

- $\quad$ Q-squared for the predictive validity of the survey from a nonparametric perspective; acceptable Q-squared values, and their R-square values, must be greater than 0 .

- Cronbach's alpha and compound reliability index for internal variability of the latent variables; internal validity can be estimated based on the variance or correlation index between the items of a latent variable [61], and acceptable values must be greater than 0.7.

- Average variance extracted (AVE) for the convergent validity of the items in the latent variables; acceptable values must be greater than 0.5 .

- Average block variance inflation factor (VIF) and average full collinearity VIF (AFVIF) for the collinearity of the items in the latent variables; acceptable values must be less than 3.3 . 


\subsection{Stage 5: Structural Equation Model}

The 4 latent variables were integrated into a structural equation model (SEM), as illustrated in Figure 1, with 6 research hypotheses. In addition, the SEM was tested using partial least squares (PLS), which is widely accepted in multiple disciplines [62]. Also, the greatest advantage of an SEM is its ability to model and illustrate, at the same time, the direct and indirect interrelations between multiple dependent and independent latent variables, because the latent variables have different roles, as dependent and independent, in this research. Likewise, SEMs are reliable even using nonnormal data, small samples, or ordinal data [63].

The research hypotheses shown in Figure 1 were tested using WarpPLS v.6.0 $0^{\circledR}$ software (ScriptWarp Systems, Laredo, TX, USA, 2017), which is based on PLS; it is widely recommended by Kock [64], and some PLS applications can be found, for instance, in Midiala Oropesa, et al. [65], who modeled the effects of Kaizen in an industrial context, or in García-Alcaraz, et al. [66], who modeled the effects of Just in Time (JIT) in the manufacturing industry.

The model was tested with a $95 \%$ reliability level, implying that the $p$-values of the parameters had to be lower than 0.05 . Before interpreting the SEM, 6 efficiency models and quality indices were calculated, proposed by Kock [60]:

- Average path coefficient (APC): statistically validates the hypotheses in a generalized way. The $p$-value must be less than 0.05 .

- $\quad$ Average R-squared (ARS) and average adjusted R-squared (AARS): measure the model's predictive validity. Acceptable $p$-values for ARS and AARS must be less than 0.05 . The null hypotheses to be tested are APC $=0$ and ARS $=0$ against the alternative hypotheses, where $\mathrm{APC} \neq 0$ and $\mathrm{ARS} \neq 0$.

- Average variance inflation factor (AVIF) and average full collinearity VIF (AFVIF): measure the level of collinearity between the latent variables. The acceptable value must be less than 3.3.

- Tenenhaus goodness of fit (GoF): measures the explanatory power of the model. The GoF value must be greater than 0.36 .

\subsubsection{Direct Effects}

The direct effects in the model were evaluated and are illustrated in Figure 1 by arrows directly connecting two latent variables, where each arrow represents a hypothesis. In addition, each effect has a $\beta$ value and a $p$-value; $\beta$ expresses dependency in standard deviations between an independent and a dependent latent variable, whereas $p$-value is for the hypothesis test where the null hypothesis is $\beta_{1}=0$, which is tested against the alternative hypothesis, $\beta_{1} \neq 0$ [60]. Additionally, $R^{2}$ for the dependent variables was estimated as a coefficient that shows the amount of variance in a dependent latent variable that is explained by an independent latent variable.

\subsubsection{Indirect Effects and Total Effects}

In SEMs, indirect effects occur between 2 latent variables through other latent variables, known as mediators. Indirect effects also have $p$-values to determine whether they are statistically significant or not. On the other hand, total effects in a relationship are the total direct and indirect effects; total effects also have associated $p$-values.

Finally, for each effect (direct, indirect, or total), the effect size for decomposition of R-squared was estimated when 2 or more independent latent variables influenced a dependent latent variable.

\subsubsection{Sensitivity Analysis}

Frequently, the relationship between the latent variables is not explained enough by $\beta$ values and it is necessary to know different scenarios for them. In this research, for every relationship or hypothesis in Figure 1, the probability of occurrence for 2 scenarios is analyzed when each variable occurs independently with low and high values. A third scenario represents the probability of the 
combination of both variables in a hypothesis when they occur simultaneously, while a fourth scenario is about the probability that the dependent variable will occur in a high or low scenario because the independent variable has occurred in a high or low scenario (a conditional probability). Since the latent variables are standardized, values greater than 1 represent high scenarios in a latent variable, while values less than 1 represent low scenarios for a latent variable.

In this research, scenarios with low values are represented by a minus sign $(-)$ and scenarios with high values are represented by a plus sign (+). In the same way, the probability of simultaneous or simultaneous occurrence of scenarios between 2 variables (low or high) is represented by an ampersand (\&). Finally, the conditional probability of occurrence of a scenario in a dependent latent variable because the scenario for the dependent variable has happened is represented by "If."

In addition, since the automotive industrial sector in this geographic context is one of the most representative in previous surveys reported by Mendoza-Fong, et al. [67], that sector is compared with other sectors to find significant differences among them, so that a model is executed for the automotive sector and a model is rejected for others, and differences in $\beta$ are tested.

\section{Results}

\subsection{Sample Description}

After four months of survey administration, 368 questionnaires were collected. Table 3 lists the surveyed industrial sectors and the respondents' job positions. As can be observed, most of the sample is from the automotive industry ( 74 technicians, 41 operators, 32 engineers, 22 supervisors, 1 manager, and 2 other job positions).

Table 3. Industrial sector vs. job position.

\begin{tabular}{cccccccc}
\hline \multirow{2}{*}{ Job Position } & \multicolumn{7}{c}{ Industrial Sector } \\
\cline { 2 - 8 } & Aeronautics & Electrics & Automotive & Electronics & Medical & Other & Total \\
\hline technician & 0 & 21 & 74 & 29 & 7 & 11 & 142 \\
operator & 1 & 4 & 41 & 11 & 10 & 12 & 79 \\
engineer & 3 & 6 & 32 & 7 & 4 & 1 & 53 \\
supervisor & 1 & 9 & 22 & 8 & 2 & 6 & 48 \\
manager & 0 & 1 & 1 & 1 & 2 & 1 & 6 \\
other & 0 & 0 & 2 & 0 & 0 & 1 & 3 \\
\hline total & 5 & 41 & 172 & 56 & 25 & 32 & 331 \\
\hline
\end{tabular}

Also, only 331 respondents provided information. Most of the respondents are maintenance technicians or operators; together the categories represent $66.67 \%$ of the sample. Such results imply that the data collected from the survey were obtained from people directly involved in equipment maintenance.

\subsection{Survey Statistical Validation}

Table 4 presents the estimated coefficients or indices for the latent variables. Based on these indices, we concluded that the latent variables have enough parametric and nonparametric predictive validity, internal validity, and convergent validity. Similarly, according to the VIF values, the latent variables are free from internal collinearity problems. Consequently, because the latent variables passed the validation process, they were integrated into the model and evaluated. 
Table 4. Survey validation.

\begin{tabular}{ccccc}
\hline Index & $\begin{array}{c}\text { Managerial } \\
\text { Commitment }\end{array}$ & $\begin{array}{c}\text { TPM } \\
\text { Implementation }\end{array}$ & $\begin{array}{c}\text { PM } \\
\text { Implementation }\end{array}$ & $\begin{array}{c}\text { Productivity } \\
\text { Benefits }\end{array}$ \\
\hline R-squared & - & 0.628 & 0.407 & 0.382 \\
adj. R-squared & - & 0.626 & 0.405 & 0.377 \\
composite reliability & 0.942 & 0.939 & 0.902 & 0.956 \\
cronbach's alpha & 0.926 & 0.928 & 0.873 & 0.948 \\
average & 0.729 & 0.608 & 0.569 & 0.732 \\
variance inflation factor & 2.560 & 2.804 & 1.982 & 1.499 \\
Q-squared & - & 0.630 & 0.409 & 0.381 \\
\hline
\end{tabular}

\subsection{Structural Equation Model}

Table 5 shows the model fit and estimated quality indices in the model. Based on the APC, ARS, and AARS values, the model has enough predictive validity. Similarly, the VIF and AFVIF values demonstrate that the model is free from collinearity problems, whereas GoF shows that the model fits the data. According to these data, the effects between the variables can be interpreted.

Table 5. Model fit and quality indices.

\begin{tabular}{cc}
\hline Index & Value \\
\hline average path coefficient (APC) & $0.368, p<0.001$ \\
average R-squared (ARS) & $0.472, p<0.001$ \\
average adjusted R-squared (AARS) & $0.470, p<0.001$ \\
average block VIF (AVIF); acceptable if $\leq 5$, ideally $\leq 3.3$ & 1.912 \\
average full collinearity VIF (AFVIF); acceptable if $\leq 5$, ideally $\leq 3.3$ & 2.211 \\
tenenhaus goodness of fit (GoF); small $\geq 0.1$, medium $\geq 0.25$, large $\geq 0.36$ & 0.558 \\
\hline
\end{tabular}

\subsubsection{Direct Effects}

Figure 2 presents the model results once the latent variable coefficients, model fit, and quality indices were estimated. As can be inferred from the $p$-values, all direct effects or direct relationships between the latent variables are statistically significant with a 95\% reliability level. Table 6 summarizes the conclusions regarding the research hypotheses. All of the research hypotheses were accepted, since they are statistically significant.

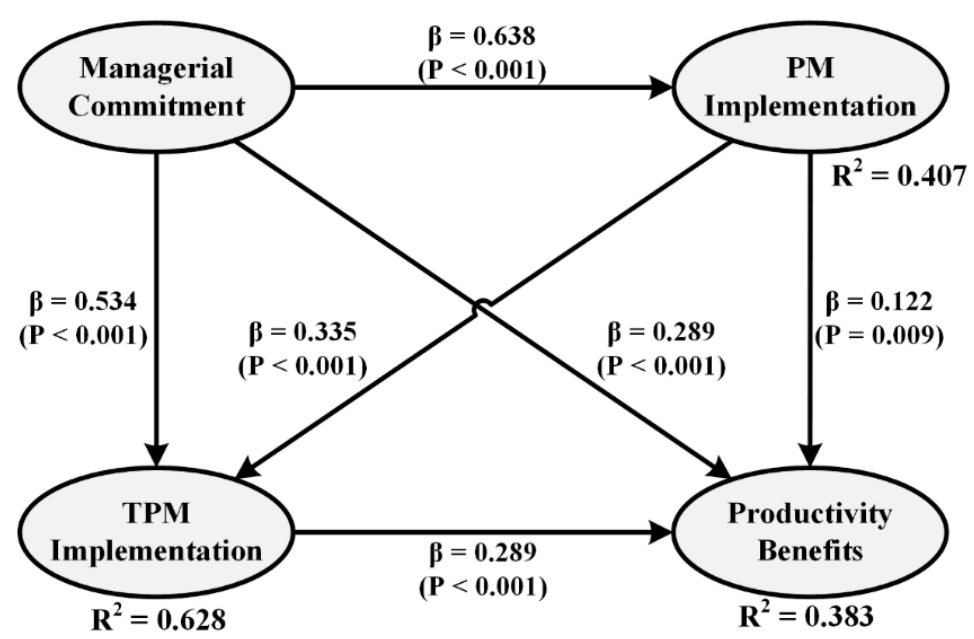

Figure 2. Evaluated model. 
Table 6. Hypothesis validation.

\begin{tabular}{cclccc}
\hline Hypothesis & Independent Variable & Dependent Variable & $\boldsymbol{\beta}$ & $\boldsymbol{p}$-Value & Conclusion \\
\hline H1 & managerial commitment & TPM implementation & 0.534 & $<0.001$ & accepted \\
H2 & managerial commitment & PM implementation & 0.638 & $<0.001$ & accepted \\
H3 & PM implementation & TPM implementation & 0.335 & $<0.001$ & accepted \\
H4 & managerial commitment & productivity benefits & 0.289 & $<0.001$ & accepted \\
H5 & TPM implementation & productivity benefits & 0.289 & $<0.001$ & accepted \\
H6 & PM implementation & productivity benefits & 0.122 & $=0.009$ & accepted \\
\hline
\end{tabular}

Figure 2 also shows the $R^{2}$ values from the dependent latent variables. In SEMs, $R^{2}$ expresses the amount of variance in a dependent variable that is explained by one or more independent variables. For instance, the TPM implementation latent variable shows $R^{2}=0.628$, which is explained by managerial commitment (0.400) and PM implementation (0.228). In turn, PM implementation is explained by only one latent variable, managerial commitment, with $R^{2}=0.407$.

Finally, the productivity benefits latent variable is explained in 0.382 units by three latent variables: managerial commitment (0.162), PM implementation (0.057), and TPM implementation (0.164). These results imply that to ensure proper TPM implementation, it is important to perform tasks from managerial commitment, since this latent variable explains $40 \%$ of the PM implementation. Similarly, to obtain productivity benefits, companies must have managerial commitment and TPM implementation, because those variables have a higher explanatory level.

\subsubsection{Indirect Effects}

Figure 2 displays four indirect effects, the $p$-value for its statistical validation, and the size effect (SE) as an explanatory power: three of them occur through two segments, and one occurs through three segments. Similarly, Table 7 lists the sum of indirect effects and associates them with their corresponding $p$-values and SEs. For instance, managerial commitment is indirectly related to TPM implementation through PM implementation. This indirect relationship is statistically significant $(p<0.001)$ and has a value of 0.214 , explaining $16.0 \%$ of variability.

Table 7. Indirect effects.

\begin{tabular}{ccc}
\hline \multirow{2}{*}{ Dependent Variable } & \multicolumn{2}{c}{ Independent Variable } \\
\cline { 2 - 3 } & Managerial Commitment & PM Implementation \\
\hline \multirow{2}{*}{ TPM implementation } & $0.214 p<0.001$ & - \\
\hline \multirow{2}{*}{ productivity benefits } & $\mathrm{ES}=0.160$ & $0.097 p=0.004$ \\
& $0.293 p<0.001$ & $\mathrm{ES}=0.045$ \\
\hline
\end{tabular}

Likewise, the managerial commitment latent variable has an indirect effect on productivity benefits through two latent variables, TPM implementation and PM implementation; the value of this indirect effect is 0.293 and it can explain $16.5 \%$ of variability. Finally, PM implementation has an indirect effect on productivity benefits through TPM implementation with a low value of 0.097 , but it is still statistically significant and can explain $4.5 \%$ of variability.

\subsubsection{Total Effects}

Total effects in a relationship are total direct and indirect effects. In this sense, Table 8 shows the total effects found in the model, the $p$-value associated with the statistical test, and the size effect. For instance, the total effects in the relationship between managerial commitment and productivity benefits $(0.582)$ consists of the total direct effect $(0.289)$ and the indirect effect $(0.232)$. 


\subsubsection{Sensitivity Analysis}

Table 9 presents the probabilities of occurrence independently for the latent variables analyzed by their high and low scenarios. For example, it is observed that the probability that managerial commitment is presented at a low level is only 0.158 , which represents a risk for the maintenance manager, since it fully demonstrates that TPM implementation can only be possible if there is precedence for it. Similarly, the probability of having managerial commitment in a high scenario is 0.190 . Interpretations of the other latent variables are performed in a similar way; in this case, the low levels represent a risk or an improvement opportunity for maintenance managers to avoid this occurrence.

Table 8. Total effects.

\begin{tabular}{|c|c|c|c|}
\hline \multirow{2}{*}{ Dependent Variable } & \multicolumn{3}{|c|}{ Independent Variable } \\
\hline & $\begin{array}{l}\text { Managerial } \\
\text { Commitment }\end{array}$ & $\begin{array}{c}\text { TPM } \\
\text { Implementation }\end{array}$ & $\begin{array}{c}\text { PM } \\
\text { Implementation }\end{array}$ \\
\hline TPM implementation & $\begin{array}{c}0.748 p<0.001 \\
\mathrm{ES}=0.561\end{array}$ & - & $\begin{array}{c}0.335 p<0.001 \\
\mathrm{ES}=0.228\end{array}$ \\
\hline PM implementation & $\begin{array}{c}0.638 p<0.001 \\
\mathrm{ES}=0.407\end{array}$ & - & - \\
\hline productivity benefits & $\begin{array}{c}0.582 p<0.001 \\
\mathrm{ES}=0.326\end{array}$ & $\begin{array}{c}0.289 p<0.001 \\
\mathrm{ES}=0.164\end{array}$ & $\begin{array}{c}0.218 p<0.001 \\
\mathrm{ES}=0.102\end{array}$ \\
\hline
\end{tabular}

Table 9. Scenarios and probabilities of independent occurrence.

\begin{tabular}{ccc}
\hline Latent Variable & Scenario & Probability \\
\hline \multirow{2}{*}{ managerial commitment } & - & 0.158 \\
& + & 0.190 \\
\hline \multirow{2}{*}{ TPM implementation } & - & 0.160 \\
& + & 0.166 \\
\hline \multirow{2}{*}{ PM implementation } & - & 0.190 \\
& + & 0.179 \\
\hline \multirow{2}{*}{ productivity benefits } & - & 0.155 \\
& + & 0.190 \\
\hline
\end{tabular}

According to the previous information and based on the values of the variables in their low scenarios, one of the biggest risks is to have a failure in the PM implementation process, since there is a probability of 0.190 . Consequently, managers must work hard to generate a work culture focused on preservation of production equipment, because according to the model presented in Figure 1, the success of a more complete program depends on it, as the TPM implementation. Likewise, it is observed that two latent variables have a high probability of occurrence in their high scenarios, managerial commitment and productivity benefits, with 0.190 , therefore managers must focus their efforts on increasing those values.

Table 10 shows the high and low scenario combinations for the variables analyzed, where the dependent variables are presented in rows and the independent variables in columns, although each value in every relationship can be discussed. In this section, some of them are analyzed in an illustrative way. In addition, for each of the intersections, the probability of occurring simultaneously for the two variables is represented by " $\&$ " and the conditional probability of occurrence of a dependent variable because the independent variable has occurred is represented by "If." Thus, there are scenarios that are pessimistic where the two levels of the variables are low, and there are scenarios that are optimistic because the two variables are at their high level. 
Table 10. Scenarios and probabilities for independent occurrence.

\begin{tabular}{|c|c|c|c|c|c|c|c|}
\hline \multirow{3}{*}{$\begin{array}{l}\text { Dependent } \\
\text { Variable }\end{array}$} & \multirow[b]{3}{*}{ Scenario } & \multicolumn{6}{|c|}{ Independent Variable } \\
\hline & & \multicolumn{2}{|c|}{$\begin{array}{l}\text { Managerial } \\
\text { Commitment }\end{array}$} & \multicolumn{2}{|c|}{ TPM Implementation } & \multicolumn{2}{|c|}{ PM Implementation } \\
\hline & & - & + & - & + & - & + \\
\hline \multirow{2}{*}{$\begin{array}{c}\text { TPM } \\
\text { implementation }\end{array}$} & - & $\begin{array}{l}\&=0.098 \\
\text { If }=0.621\end{array}$ & $\begin{array}{l}\&=0.003 \\
\text { If }=0.016\end{array}$ & & & & \\
\hline & + & $\begin{array}{l}\&=0.005 \\
\text { If }=0.034\end{array}$ & $\begin{array}{l}\&=0.095 \\
\text { If }=0.565\end{array}$ & & & & \\
\hline \multirow{2}{*}{$\begin{array}{c}\text { PM } \\
\text { implementation }\end{array}$} & - & $\begin{array}{l}\&=0.090 \\
\text { If }=0.569\end{array}$ & $\begin{array}{l}\&=0.008 \\
\text { If }=0.048\end{array}$ & $\begin{array}{l}\&=0.092 \\
\text { If }=0.486\end{array}$ & $\begin{array}{l}\&=0.003 \\
\text { If }=0.014\end{array}$ & & \\
\hline & + & $\begin{array}{l}\&=0.008 \\
\text { If }=0.052\end{array}$ & $\begin{array}{l}\&=0.084 \\
\text { If }=0.500\end{array}$ & $\begin{array}{l}\&=0.005 \\
\text { If }=0.030\end{array}$ & $\begin{array}{l}\&=0.087 \\
\text { If }=0.485\end{array}$ & & \\
\hline \multirow{2}{*}{$\begin{array}{l}\text { productivity } \\
\text { benefits }\end{array}$} & - & $\begin{array}{l}\&=0.065 \\
\text { If }=0.414\end{array}$ & $\begin{array}{l}\&=0.00 \\
\text { If }=0.00\end{array}$ & $\begin{array}{l}\&=0.076 \\
\text { If }=0.475\end{array}$ & $\begin{array}{l}\&=0.003 \\
\text { If }=0.016\end{array}$ & $\begin{array}{l}\&=0.065 \\
\text { If }=0.343\end{array}$ & $\begin{array}{l}\&=0.003 \\
\text { If }=0.015\end{array}$ \\
\hline & + & $\begin{array}{l}\&=0.027 \\
\text { If }=0.172\end{array}$ & $\begin{array}{l}\&=0.068 \\
\text { If }=0.403\end{array}$ & $\begin{array}{l}\&=0.027 \\
\text { If }=0.169\end{array}$ & $\begin{array}{l}\&=0.065 \\
\text { If }=0.393\end{array}$ & $\begin{array}{l}\&=0.024 \\
\text { If }=0.129\end{array}$ & $\begin{array}{l}\&=0.063 \\
\text { If }=0.348\end{array}$ \\
\hline
\end{tabular}

For instance, a pessimistic scenario can occur when managerial commitment and PM implementation have simultaneously low levels, which has a simultaneous probability of 0.090 , representing a risk for the maintenance manager. However, the probability of the second latent variable occurring since the first variable has happened is 0.569 ; in other words, if there is a low managerial commitment to implementation of the maintenance program, the probability is 0.569 that the policies focused on machinery and equipment preservation are also at their low level. In order to avoid these scenarios during the TPM implementation process, it is important to have managerial commitment at its high level, since the probability that this scenario is presented along with a low level in PM implementation is only 0.008 , which indicates that it will almost never happen, which shows the importance of that variable. Also, the probability of having a low level in PM implementation because there is a high managerial commitment level is 0.048 , a very low value that indicates that the second variable in high levels is not associated with low levels in first variable.

The above statement is easily demonstrated when the scenario is analyzed with the variables inverted, that is, when managerial commitment is low and PM implementation is high, which can occur simultaneously at a probability of 0.008 , and this indicates that it will almost never happen. Also, it is observed that it is very unlikely that the second variable will occur in its scenario because the first variable has happened, since the probability is only 0.052 . However, when managerial commitment and PM implementation have high levels simultaneously, there is a probability of occurrence of 0.084 , but the probability that the second variable occurs at its high level since the first variable occurred at its high level is 0.500 . The previous data clearly indicate that high managerial commitment levels are related to high PM implementation levels.

How does TPM implementation impact productivity benefits? In order to answer this question, the situation where the first variable is independent and the second is dependent is analyzed. In this case, in the pessimistic environment, when the two variables are at their low level, it is observed that there is a probability of 0.076 that this scenario will occur. However, the probability of having low productivity benefits because the TPM implementation at its low level is 0.475 , which indicates that the low levels of the second variable are related to the low levels of the first. Additionally, in an optimistic environment, when TPM implementation and productivity benefits have high levels, the probability that they will occur simultaneously is 0.065 , which represents a low value for a maintenance manager; however, the probability that the second variable will occur because the second variable has occurred in its scenario is 0.393 . The previous data indicate that TPM implementation is a program that guarantees productivity benefits. 
In addition, the previous statement is easily validated when the probability of TPM implementation is at a high level and productivity benefits is at a low level, which has a value of 0.003 , indicating that this scenario will almost never occur. Also, the probability that the second variable is at its low level because the first variable is at its high level is only 0.016 , which indicates that TPM implementation at a high level is not associated with productivity benefits at a low level. Due to space problems, the interpretation of other scenarios between the latent variables is left to the reader, with an explanation similar to the one that is presented.

A structural equation model was executed, integrating data from the automotive sector, with 172 cases, and another model integrates 159 cases from the aeronautics, electric, electronics, medical, and other sectors. Table 11 shows the $\beta$ values for every model in the multigroup analysis, for example, for the relationship between managerial commitment and PM implementation for the automotive model it is 0.654 and for the same relationship in the other sectors model it is 0.631 , a similar value that needs to be tested statistically for its difference.

Table 11. Beta values for models.

\begin{tabular}{ccccccc}
\hline & \multicolumn{3}{c}{ Automotive Sector } & \multicolumn{3}{c}{ Other Sectors } \\
\cline { 2 - 7 } Dependent Variable & \multicolumn{5}{c}{ Independent Variable } \\
\cline { 2 - 7 } & MC & PMI & TPMI & MC & PMI & TPMI \\
\hline PM implementation & 0.654 & - & - & 0.631 & - & - \\
TPM implementation & 0.49 & 0.364 & - & 0.573 & 0.298 & - \\
productivity benefits & 0.277 & 0.233 & 0.436 & 0.304 & 0.210 & 0.359 \\
\hline MC, managerial commitment; PMI, PM implementation; TPMI, TPM implementation.
\end{tabular}

Table 12 shows the confidence intervals for differences between two $\beta$ values in the analyzed models (automotive sector and other sectors) at a 95\% confidence level. For every $\beta$ value, it is observed that the lower confidence value limit is negative and the upper confidence value limit is positive, and this lets us conclude that there are no differences between analyzed groups, because the zero value is included in that interval.

Table 12. Confidence intervals for differences in $\beta$.

\begin{tabular}{cccc}
\hline \multirow{2}{*}{ Dependent Variable } & \multicolumn{3}{c}{ Independent Variable } \\
\cline { 2 - 4 } & $\begin{array}{c}\text { Managerial } \\
\text { Commitment }\end{array}$ & $\begin{array}{c}\text { TPM } \\
\text { Implementation }\end{array}$ & $\begin{array}{c}\text { PM } \\
\text { Implementation }\end{array}$ \\
\hline TPM implementation & -0.098 to 0.1333 & - & - \\
\hline PM implementation & -0.069 to 0.141 & -0.096 to 0.115 & - \\
\hline productivity benefits & -0.032 to 0.178 & -0.035 to 0.174 & -0.104 to 0.107 \\
\hline
\end{tabular}

\section{Conclusions and Industrial Implications}

Based on the findings previously discussed, the research conclusions are as follows:

1. Based on the $R^{2}$ values, TPM implementation has a $62.8 \%$ dependence on two variables, but managerial commitment explains most of the variability in $40 \%$. In this sense, manufacturing companies must encourage department leaders and managers to embrace their responsibility for and commitment to TPM. Similarly, managers must promote the active participation of maintenance staff and communicate a corporate vision centered on quality and equipment maintenance, and among these aspects, they must be actively involved in TPM projects. Two other responsibilities of senior managers are to make sure that staff commitment to TPM is aligned with the corporate mission and supervise tracking of the implemented maintenance plans. 
2. The managerial commitment latent variable explains $40.7 \%$ of PM implementation variability. Therefore, for a preventive maintenance program to be successful, managerial commitment is necessary. Hence, PM programs must be focused on adjusting and changing components before the equipment fails. Also, preventing machine failures must be promoted by managers, since they need to understand the components' life cycle and generate a replacement plan.

3. TPM is a set of programs, among which is preventive maintenance. According to the findings, PM implementation is an important antecedent to any comprehensive TPM program. In fact, in this research, PM implementation explains $22.8 \%$ of the variability of TPM implementation. These findings imply that TPM managers and operators must focus their efforts on preventive maintenance programs that consider the components' life cycle to make changes before machines fail.

4. Statistically, three latent variables explain $38.3 \%$ of the productivity benefits latent variable: TPM implementation (16.4\%), managerial commitment (16.2\%), and PM implementation (5.7\%). Such estimates imply that managers must pay close attention to the first two variables, since they have the largest effects. Although the direct impact from PM implementation is low in productivity benefits, the indirect effect has a value of 0.097 , which can explain $4.55 \%$. In the end, the total effects of PM implementation on productivity benefits have a value of 0.218 units, and this latent variable explains up to $10.2 \%$. In other words, preventive maintenance as a part of TPM implementation is vital if companies aim to obtain productivity benefits.

5. The total effects of managerial commitment are larger than 0.5 standard deviations, demonstrating that this variable is a key element in productivity, TPM success, and PM programs. Consequently, TPM operators must always demand managerial support before starting any preventive maintenance program, because managerial commitment on its own does not guarantee all the productivity benefits, since its direct effects on this variable were only 0.289 . On the other hand, the total effects of managerial commitment on productivity benefits where the TPM and PM were involved had a value of 0.582 .

6. It is interesting to observe the relationship between managerial commitment and productivity benefits obtained from TPM, where the direct effect was only 0.289 , but the indirect effect that occurs through the mediating variables PM implementation and TPM implementation was 0.293, that is, the indirect effect is greater than the direct effect, and the sum gives a total effect of 0.582 . The foregoing indicates that management commitment is not sufficient to obtain productivity benefits, because it is necessary to have a labor culture focused on conserving the machinery and equipment that can be reflected in a preventive maintenance program, but in addition, a more holistic TPM implementation program in which all departments of the company are integrated is required.

7. Based on information in Table 10, the following conclusions can be summarized:

a. High managerial commitment levels are not associated with low productivity benefits levels, even if the probability of simultaneous occurrence is zero.

b. Even if managerial commitment is low, it is possible to obtain high productivity benefits, because these may come from other sources.

c. Having low managerial commitment levels represent a risk in PM implementation, TPM implementation, and productivity benefits.

d. High TPM implementation levels guarantee high productivity benefits levels.

8. There is no statistical evidence to declare that the automotive industrial sector is different from other sectors when multiple groups are analyzed. 


\section{Research Limitations and Suggestions for Future Work}

TPM offers a broad range of benefits for companies, yet this research only analyzes the impact of TPM on productivity. This is one of the limitations in the study, and in order to address it, further research would have to expand the scope by considering other benefits, such as employee safety benefits and organizational benefits. Another limitation in the proposed model and its hypotheses is that it was evaluated using information from the Mexican maquiladora industry, and the same model using data from other geographical areas and industrial sectors may have different results.

Similarly, a successful TPM implementation is not the result of just managerial commitment and PM programs; it is important to explore the impact of other critical success factors, such as machinery technology, employee commitment, employee education and training, tool maintenance, and equipment, and as a result, R-squared is not equal to 1 , because another latent variable is not integrated into the model.

Author Contributions: J.R.D.-R. and J.L.G.-A. performed the data collection and data analysis and wrote the paper. J.C.S.D.-M., J.B.-F., and L.A.-S. contributed to the univariate and multivariate analyses and to improving the writing and readability of the paper. Finally, J.R.M.-F. reviewed the English translation and rewrote the paper.

Funding: This project was financed by the Mexican National Council for Science and Technology (CONACYT) under the Thematic Network of Industrial Processes Optimization by grant 330-18-08.

Acknowledgments: The authors acknowledge the maquiladoras companies, managers, and participants who answered the questionnaire in this research.

Conflicts of Interest: The authors declare no conflict of interest.

\section{References}

1. Tang, Y.; Liu, Q.; Jing, J.; Yang, Y.; Zou, Z. A framework for identification of maintenance significant items in reliability centered maintenance. Energy 2017, 118, 1295-1303. [CrossRef]

2. Singh, R.; Gohil, A.M.; Shah, D.B.; Desai, S. Total productive maintenance (TPM) implementation in a machine shop: A case study. Procedia Eng. 2013, 51, 592-599. [CrossRef]

3. Andersson, R.; Manfredsson, P.; Lantz, B. Total productive maintenance in support processes: An enabler for operation excellence. Total Qual. Manag. Bus. Excell. 2015, 26, 1042-1055. [CrossRef]

4. Pettersen, J. Defining lean production: Some conceptual and practical issues. TQM J. 2009, 21, 127-142. [CrossRef]

5. Nakajima, S. Total Productive Maintenance; Productivity Press: London, UK, 1998.

6. Attri, R.; Grover, S.; Dev, N.; Kumar, D. An ISM approach for modelling the enablers in the implementation of total productive maintenance (TPM). Int. J. Syst. Assur. Eng. Manag. 2013, 4, 313-326. [CrossRef]

7. Eti, M.C.; Ogaji, S.O.T.; Probert, S.D. Implementing total productive maintenance in Nigerian manufacturing industries. Appl. Energy 2004, 79, 385-401. [CrossRef]

8. Rahman, C.M.L. Assessment of Total Productive Maintenance Implementation in a Semiautomated Manufacturing Company Through Downtime and Mean Downtime Analysis. In Proceedings of the 2015 International Conference on Industrial Engineering and Operations Management (IEOM), Aveiro, Portugal, 3-5 March 2015; pp. 1-9.

9. Ahuja, I.P.S.; Khamba, J.S. Total productive maintenance: Literature review and directions. Int. J. Qual. Reliab. Manag. 2008, 25, 709-756. [CrossRef]

10. Bon, A.T.; Lim, M. Total Productive Maintenance in Automotive Industry: Issues and Effectiveness. In Proceedings of the 2015 International Conference on Industrial Engineering and Operations Management (IEOM), Aveiro, Portugal, 3-5 March 2015; pp. 1-6.

11. Barrios, L.J.; Minguillón, J.; Perales, F.J; Ron-Angevin, R.; Solé-Casals, J.; Mañanas, M.A. Estado del arte en neurotecnologías para la asistencia y la rehabilitación en españa: Tecnologías auxiliares, trasferencia tecnológica y aplicación clínica. Revista Iberoamericana de Automática e Informática Industrial RIAI 2017, 14, 355-361. [CrossRef] 
12. Ng, K.C.; Goh, G.G.G.; Eze, U.C. Critical Success Factors of Total Productive Maintenance Implementation: A Review. In Proceedings of the 2011 IEEE International Conference on Industrial Engineering and Engineering Management, Changchun, China, 6-9 December 2011; pp. 269-273.

13. Gupta, P.; Vardhan, S.; Haque, M.S.A. Study of Success Factors of TPM Implementation in Indian Industry Towards Operational Excellence: An Overview. In Proceedings of the 2015 International Conference on Industrial Engineering and Operations Management (IEOM), Aveiro, Portugal, 3-5 March 2015.

14. Gómez, A.H.; Toledo, C.E.; Prado, J.M.L.; Morales, S.N. Factores críticos de éxito para el despliegue del mantenimiento productivo total en plantas de la industria maquiladora para la exportación en ciudad juárez: Una solución factorial. Contaduría y Administración 2015, 60, 82-106. [CrossRef]

15. Shen, C.C. Discussion on key successful factors of TPM in enterprises. J. Appl. Res. Technol. 2015, 13, 425-427. [CrossRef]

16. Willmott, P.; McCarthy, D. 2-Assessing the true costs and benefits of TPM. In Total Productivity Maintenance, 2nd ed.; Butterworth-Heinemann: Oxford, UK, 2001; pp. 17-22.

17. Park, K.S.; Han, S.W. TPM—-total productive maintenance: impact on competitiveness and a framework for successful implementation. Hum. Factors Ergon. Manuf. Serv. Ind. 2001, 11, 321-338. [CrossRef]

18. Bamber, C.J.; Sharp, J.M.; Hides, M.T. Factors affecting successful implementation of total productive maintenance: A UK manufacturing case study perspective. J. Qual. Maint. Eng. 1999, 5, 162-181. [CrossRef]

19. Netland, T.H. Critical success factors for implementing lean production: The effect of contingencies. Int. J. Prod. Res. 2016, 54, 2433-2448. [CrossRef]

20. McAdam, R.; Duffner, A.-M. Implementation of total productive maintenance in support of an established total quality programme. Total. Qual. Manag. 1996, 7, 613-630. [CrossRef]

21. Kamath, N.H.; Rodrigues, L.L.R. Simultaneous consideration of TQM and TPM influence on production performance: A case study on multicolor offset machine using SD model. Perspect. Sci. 2016, 8, 16-18. [CrossRef]

22. Chlebus, E.; Helman, J.; Olejarczyk, M.; Rosienkiewicz, M. A new approach on implementing TPM in a mine-A case study. Arch. Civ. Mech. Eng. 2015, 15, 873-884. [CrossRef]

23. Ahuja, I.P.S.; Khamba, J.S. Strategies and success factors for overcoming challenges in TPM implementation in Indian manufacturing industry. J. Qual. Maint. Eng. 2008, 14, 123-147. [CrossRef]

24. AMAC. Infogramas. Available online: https://indexjuarez.com/estadisticas/infograma (accessed on 12 May 2018). (In Spanish)

25. Caralli, R.; Stevens, J.; Willke, B.; Wilson, W. The Critical Success Factor Method: Establishing a Foundation for Enterprise Security Management. Available online: https: / / resources.sei.cmu.edu/library/asset-view. cfm?assetid=7129 (accessed on 18 April 2018).

26. Piechnicki, A.S.; Herrero Sola, A.V.; Trojan, F. Decision-making towards achieving world-class total productive maintenance. Int. J. Oper. Prod. Manag. 2015, 35, 1594-1621. [CrossRef]

27. Hernández Gómez, J.A.; Noriega Morales, S.; Pérez, L.R.; Romero López, R.; Guillen Anaya, L.G. Factores críticos de éxito para la implementación estratégica del MPT: Una revisión de literatura Ingeniería Industrial. Actualidad y Nuevas Tendencias 2014, 4, 14.

28. Moghaddam, K.S. Preventive maintenance and replacement optimization on CNC machine using multiobjective evolutionary algorithms. Int. J. Adv. Manuf. Technol. 2015, 76, 2131-2146. [CrossRef]

29. Swanson, L. Linking maintenance strategies to performance. Int. J. Prod. Econ. 2001, 70, 237-244. [CrossRef]

30. McKone, K.E.; Schroeder, R.G.; Cua, K.O. The impact of total productive maintenance practices on manufacturing performance. J. Oper. Manag. 2001, 19, 39-58. [CrossRef]

31. Nourelfath, M.; Nahas, N.; Ben-Daya, M. Integrated preventive maintenance and production decisions for imperfect processes. Reliab. Eng. Syst. Saf. 2016, 148, 21-31. [CrossRef]

32. Eti, M.C.; Ogaji, S.O.T.; Probert, S.D. Reducing the cost of preventive maintenance (PM) through adopting a proactive reliability-focused culture. Appl. Energy 2006, 83, 1235-1248. [CrossRef]

33. Anis, C.; Nidhal, R.; Mehdi, R. Simultaneous determination of production lot size and preventive maintenance schedule for unreliable production system. J. Qual. Maint. Eng. 2008, 14, 161-176.

34. Shrivastava, D.; Kulkarni, M.S.; Vrat, P. Integrated design of preventive maintenance and quality control policy parameters with CUSUM chart. Int. J. Adv. Manuf. Technol. 2016, 82, 2101-2112. [CrossRef]

35. Fumagalli, L.; Macchi, M.; Giacomin, A. Orchestration of preventive maintenance interventions. In Proceedings of the 20th IFAC World Congress, Toulouse, France, 9-14 July 2017; pp. 13976-13981. 
36. Ma, L.; Dong, S.; Gong, Y.; Yu, G. Study on application of TPM in small and medium-sized enterprises. In Proceedings of the MSIE 2011, Harbin, China, 6-11 January 2011; pp. 678-681.

37. Ng, K.C.; Chong, K.E.; Goh, G.G.G. Total Productive Maintenance Strategy in a Semiconductor Manufacturer: A Case Study. In Proceedings of the 2013 IEEE International Conference on Industrial Engineering and Engineering Management, Bangkok, Thailand, 10-13 December 2013; pp. 1184-1188.

38. Rodrigues, M.; Hatakeyama, K. Analysis of the fall of TPM in companies. J. Mater. Process. Technol. 2006, 179, 276-279. [CrossRef]

39. Mwanza, B.G.; Mbohwa, C. Design of a total productive maintenance model for effective implementation: Case study of a chemical manufacturing company. Procedia Manuf. 2015, 4, 461-470. [CrossRef]

40. Tsuchiya, S. Quality Maintenance: Zero Defects through Equipment Management; Productivity Press: London, UK, 1992.

41. Chan, F.T.S.; Lau, H.C.W.; Ip, R.W.L.; Chan, H.K.; Kong, S. Implementation of total productive maintenance: A case study. Int. J. Prod. Econ. 2005, 95, 71-94. [CrossRef]

42. Smith, R.; Mobley, R.K. Chapter 7-Total productive maintenance. In Rules of Thumb for Maintenance and Reliability Engineers; Butterworth-Heinemann: Burlington, VT, USA, 2008; pp. 107-120.

43. Campuzano-Cervantes, J.; Meléndez-Pertuz, F.; Núñez-Perez, B.; Simancas-García, J. Sistema de monitoreo electrónico de desplazamiento de tubos de extensión para junta expansiva. Revista Iberoamericana de Automática e Informática Industrial RIAI 2017, 14, 268-278. [CrossRef]

44. Abhishek, J.; Rajbir, B.; Harwinder, S. Total productive maintenance (TPM) implementation practice: A literature review and directions. Int. J. Lean Six Sigma 2014, 5, 293-323.

45. Nakajima, S. Introduction to TPM: Total Productive Maintenance; Productivity Press: Cambridge, MA, USA, 1988.

46. Nakajima, S. TPM Development Program: Implementing Total Productive Maintenance; Productivity Press: Cambridge, MA, USA, 1989.

47. Lycke, L. Team development when implementing TPM. Total. Qual. Manag. Bus. Excell. 2003, 14, $205-213$. [CrossRef]

48. Ahmad, N.; Hossen, J.; Ali, S.M. Improvement of overall equipment efficiency of ring frame through total productive maintenance: A textile case. Int. J. Adv. Manuf. Technol. 2018, 94, 239-256. [CrossRef]

49. Chong, M.Y.; Chin, J.F.; Hamzah, H.S. Transfer of total productive maintenance practice to supply chain. Total Qual. Manag. Bus. Excell. 2012, 23, 467-488. [CrossRef]

50. Ahuja, I.P.S.; Khamba, J.S. An evaluation of TPM initiatives in Indian industry for enhanced manufacturing performance. Int. J. Qual. Reliab. Manag. 2008, 25, 147-172. [CrossRef]

51. Kalir, A.A.; Rozen, K.; Morrison, J.R. Evaluation of preventive maintenance segregation: A multi factorial study. IEEE Trans. Semicond. Manuf. 2017, 30, 508-514. [CrossRef]

52. Chalabi, N.; Dahane, M.; Beldjilali, B.; Neki, A. Optimisation of preventive maintenance grouping strategy for multi-component series systems: Particle swarm based approach. Comput. Ind. Eng. 2016, 102, 440-451. [CrossRef]

53. Avelar-Sosa, L.; García-Alcaraz, J.L.; Vergara-Villegas, O.O.; Maldonado-Macías, A.A.; Alor-Hernández, G. Impact of traditional and international logistic policies in supply chain performance. Int. J. Adv. Manuf. Technol. 2015, 76, 913-925. [CrossRef]

54. Duenckel, J.R.; Soileau, R.; Pittman, J.D. Preventive maintenance for electrical reliability: A proposed metric using mean time between failures plus finds. IEEE Ind. Appl. Mag. 2017, 23, 45-56. [CrossRef]

55. Leys, C.; Ley, C.; Klein, O.; Bernard, P.; Licata, L. Detecting outliers: Do not use standard deviation around the mean, use absolute deviation around the median. J. Exp. Soc. Psychol. 2013, 49, 764-766. [CrossRef]

56. Hair, J.F.J.; Black, W.C.; Babin, B.J.; Anderson, R.E. Multivariate Data Analysis; Prentice Hall: Upper Saddle River, NJ, USA, 2013.

57. Lynch, S.M. Introduction to Applied Bayesian Statistics and Estimation for Social Scientists; Springer Science \& Business Media: New York, NY, USA, 2007.

58. Kohler, M.; Müller, F; Walk, H. Estimation of a regression function corresponding to latent variables. J. Stat. Plan. Inference 2015, 162, 22. [CrossRef]

59. Tabachnick, B.; Fidell, L. Using Multivariate Statistics, 2nd ed.; Pearson: Chennai, India, 2013.

60. Kock, N. Warppls 5.0 User Manual; ScriptWarp Systems: Laredo, TX, USA, 2015. 
61. Adamson, K.A.; Prion, S. Reliability: Measuring internal consistency using Cronbach's $\alpha$. Clin. Simul. Nurs. 2013, 9, e179-e180. [CrossRef]

62. Evermann, J.; Tate, M. Assessing the predictive performance of structural equation model estimators. J. Bus. Res. 2016, 69, 4565-4582. [CrossRef]

63. Jenatabadi, H.S.; Ismail, N.A. Application of structural equation modelling for estimating airline performance. J. Air Transp. Manag. 2014, 40, 25-33. [CrossRef]

64. Kock, N. Advanced mediating effects tests, multi-group analyses, and measurement model assessments in PLS-based SEM. Int. J. e-Collab. 2014, 10, 1-13. [CrossRef]

65. Midiala Oropesa, V.; Jorge Luis García, A.; Aidé Aracely Maldonado, M.; Valeria Martínez, L. The impact of managerial commitment and kaizen benefits on companies. J. Manuf. Technol. Manag. 2016, 27, 692-712. [CrossRef]

66. García-Alcaraz, J.L.; Prieto-Luevano, D.J.; Maldonado-Macías, A.A.; Blanco-Fernández, J.; Jiménez-Macías, E.; Moreno-Jiménez, J.M. Structural equation modeling to identify the human resource value in the JIT implementation: Case maquiladora sector. Int. J. Adv. Manuf. Technol. 2015, 77, 1483-1497. [CrossRef]

67. Mendoza-Fong, J.R.; García-Alcaraz, J.L.; Ochoa-Domínguez, H.d.J.; Cortes-Robles, G. Green production attributes and its impact in company's sustainability. In New Perspectives on Applied Industrial Tools and Techniques; García-Alcaraz, J.L., Alor-Hernández, G., Maldonado-Macías, A.A., Sánchez-Ramírez, C., Eds.; Springer: Cham, Switerland, 2018; pp. 23-46.

(C) 2018 by the authors. Licensee MDPI, Basel, Switzerland. This article is an open access article distributed under the terms and conditions of the Creative Commons Attribution (CC BY) license (http://creativecommons.org/licenses/by/4.0/). 